\title{
Highly Proton Conductive Phosphoric Acid-Nonionic Surfactant Lyotropic Liquid Crystalline Mesophases and Application in Graphene Optical Modulators
}

\author{
Ebrima Tunkara, ${ }^{\dagger}$ Cemal Albayrak, ${ }^{\dagger}$ Emre O. Polat, ${ }^{\ddagger}$ Coskun Kocabas, ${ }^{\ddagger}$ and Ömer Dag ${ }^{*}+$ \\ ${ }^{\dagger}$ Department of Chemistry and ${ }^{\ddagger}$ Department of Physics, Bilkent University, 06800, Ankara, Turkey
}

\begin{abstract}
Proton conducting gel electrolytes are very important components of clean energy devices. Phosphoric acid $\left(\mathrm{PA}_{3} \mathrm{H}_{3} \mathrm{PO}_{4} \cdot \mathrm{H}_{2} \mathrm{O}\right)$ is one of the best proton conductors, but needs to be incorporated into some matrix for real device applications, such as into lyotropic liquid crystalline mesophases (LLCMs). Herein, we show that PA and nonionic surfactant $\left(\mathrm{NS}, \mathrm{C}_{12} \mathrm{H}_{25}\left(\mathrm{OCH}_{2} \mathrm{CH}_{2}\right){ }_{10} \mathrm{OH}, \mathrm{C}_{12} \mathrm{E}_{10}\right)$ molecules self-assemble into PANS-LLCMs and display high proton conductivity. The content of the PANS-LLCM can be as high $75 \%$ $\mathrm{H}_{3} \mathrm{PO}_{4} \cdot \mathrm{H}_{2} \mathrm{O}$ and $25 \%$ 10-lauryl ether $\left(\mathrm{C}_{12} \mathrm{H}_{25}\left(\mathrm{OCH}_{2} \mathrm{CH}_{2}\right)_{10} \mathrm{OH}, \mathrm{C}_{12} \mathrm{E}_{10}\right)$, and the mesophase follows the usual LLC trend, bicontinuous cubic $\left(\mathrm{V}_{1}\right)$-normal hexagonal $\left(\mathrm{H}_{1}\right)$ - micelle cubic $\left(\mathrm{I}_{1}\right)$, by increasing the PA concentration in the media. The PANS - LLCMs are stable under ambient conditions, as well as at high (up to $130^{\circ} \mathrm{C}$ ) and low $\left(-100^{\circ} \mathrm{C}\right)$ temperatures with a high proton conductivity, in the range of $10^{-2}$ to $10^{-6} \mathrm{~S} / \mathrm{cm}$. The mesophase

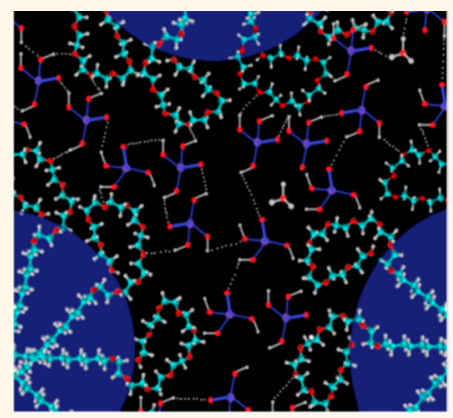
becomes a mesostructured solid with decent proton conductivity below $-100^{\circ} \mathrm{C}$. The mesophase can be used in many applications as a proton-conducting media as well as a phosphate source for the synthesis of various metal phosphates. As an application, we demonstrate a graphene-based optical modulator using supercapacitor structure formed by graphene electrodes and a PANS electrolyte. A PANS - LLC electrolyte-based supercapacitor enables efficient optical modulation of graphene electrodes over a range of wavelengths, from $500 \mathrm{~nm}$ to $2 \mu \mathrm{m}$, under ambient conditions.
\end{abstract}

KEYWORDS: phosphoric acid · lyotropic liquid crystals $\cdot$ proton conductor $\cdot$ gel electrolyte $\cdot$ graphene optical modulator

\begin{abstract}
$\Lambda$ ssembling nanostructures, clusters, ions, and molecules into mesostructures, using surfactants, is an important process for the development of advanced functional materials. Specifically, organizing ionic conductors, acids, and bases into mesophases is beneficial in the advancement of new materials and technologies. There exist many chemicals for the self-assembly of a surfactant into lyotropic liquid crystalline (LLC) mesophases, such as water, ${ }^{1-3}$ oil-water, ${ }^{4}$ aqueous solutions, ${ }^{5-7}$ ionic liquids, ${ }^{8,9} \mathrm{CO}_{2}{ }^{10}$ and salts. ${ }^{11-13}$ Furthermore, the LLC media with hydrophilic and hydrophobic domains offers a confined space for the synthesis of chemicals with unique properties. ${ }^{14-18}$ Only a few examples exist in the literature that use various acids and that investigate the influence of these acids on the existing LLC mesophases. ${ }^{19-22}$ There are also some examples in which the
\end{abstract}

acid is the surfactant such as amino acids or carboxylic acids, which are used in the presence of water as the solvent in the LLC phase. ${ }^{23-25}$ Moreover, organizing acids in the LLC phases can be very beneficial for the synthesis of porous materials that require an acidic media.

To broaden the concept of the LLC phases, we have investigated using some salts as the solvents in the assembly of surfactants. ${ }^{11-13}$ These salts have either low melting points ${ }^{11}$ or very high solubilities ${ }^{13}$ and act as solvents in the assembly of salt-surfactant mesophases, where the driving force is the softconfinement effect (SCE). ${ }^{26,27}$ The small space in the hydrophilic domain of the LLC mesophases reduces the melting point, enhances the solubility of the salts, and keeps these highly concentrated solutions stable in the hydrophilic domains of the mesophases. ${ }^{12,13}$ Usually the solvent/solution-surfactant
* Address correspondence to dag@fen.bilkent.edu.tr.

Received for review September 14, 2014 and accepted October 15, 2014.

Published online October 15, 2014 10.1021/nn505199q

(C) 2014 American Chemical Society 
interactions are strong enough to keep the salt species in the LLC phase at even very low temperatures (below liquid $\mathrm{N}_{2}$ ). ${ }^{12}$ Pure phosphoric acid is a liquid at temperatures above $42{ }^{\circ} \mathrm{C}$ and is also liquid at $\mathrm{RT}$ in the presence of as little as one water per $\mathrm{H}_{3} \mathrm{PO}_{4}$ and can be used as a solvent to form PA-nonionic surfactant LLC mesophases (PANS-LLCMs).

The hygroscopicity of compounds determines whether or not a compound can act as a solvent to assemble nonionic surfactants. ${ }^{28}$ The measure is known as the deliquescent relative humidity (DRH): above the $\mathrm{DRH}$, salts spontaneously absorb water from their surroundings and dissolve. If the compound has a very low $\mathrm{DRH}$ value, it is likely to act as a solvent in the presence of a small amount of water. $\mathrm{P}_{2} \mathrm{O}_{5}$ is one of most deliquescent compounds, and it immediately forms phosphoric acid (PA) at any humidity. Furthermore, PA is an extremely useful acid in many applications, ranging from food to bone health. It is also one of the best known proton conductors ${ }^{29-32}$ and can be beneficial for assembly into an LLC mesophase. PA has already been assembled using polymers, encapsulated into inorganic matrixes to use as proton-conducting membranes in various applications. ${ }^{29-32}$ The typical proton conductivity of PA is $0.5 \mathrm{~S} \mathrm{~cm}^{-1}$ and reduces to $10^{-3} \mathrm{~S} \mathrm{~cm}^{-1}$ in various matrixes. ${ }^{32}$ Furthermore, a confined PA can be a phosphate source to produce porous metal phosphates for battery applications. ${ }^{33}$

\section{RESULTS AND DISCUSSION}

In this investigation, we have used concentrated PA with 10-lauryl ether $\left(\mathrm{C}_{12} \mathrm{H}_{25}\left(\mathrm{OCH}_{2} \mathrm{CH}_{2}\right)_{10} \mathrm{OH}, \mathrm{C}_{12} \mathrm{E}_{10}\right)$ without any additional water to form the PANS-LLC phases. The molar and mass ratio of $P A$ to $C_{12} E_{10}$ can be as high as 20 and $75 \%$, respectively. The mesophases are bicontinuous cubic $\left(\mathrm{V}_{1}\right)$ at low, hexagonal $\left(\mathrm{H}_{1}, 2 \mathrm{D}\right.$ or 3D) at intermediate, and micelle cubic $\left(\mathrm{I}_{1}\right)$ at high PA concentrations. The PANS-LLCMs have been employed to control optical transmission of a graphene electrode in a supercapacitor geometry. PANS-based electrolytes enable us to operate graphene optical modulators in the near-IR-visible spectra.

The PANS samples diffract at small angles over a wide range of $P A / C_{12} E_{10}$ ratios, characteristic of the $L L C$ mesophases. Figure 1 shows a series of XRD patterns from various compositions. The mesophase is semistable up to $2.0 \mathrm{PA} / \mathrm{C}_{12} \mathrm{E}_{10}$ and bicontinuous cubic with a unit cell parameter $a$ of $127.1 \AA$. There is a phase transformation around a $2-3 \mathrm{PA} / \mathrm{C}_{12} \mathrm{E}_{10}$ mole ratio to a $2 \mathrm{D}$ hexagonal phase with a unit cell parameter $a$ of $55.4 \AA$. The (110) line of the 2D hexagonal phase is also weakly observed upon destroying the orientation. The phase transformation continues by increasing the PA amount; it is $3 \mathrm{D}$ hexagonal at mole ratios around 4 to 5 and becomes cubic above a mole ratio of $6 \mathrm{PA} / \mathrm{C}_{12} \mathrm{E}_{10}$, with unit cell parameters $a$ of 54.7 and $c$ of $89.3 \AA$ and $a$ of $116.7 \AA$, respectively; see Figure 1 .
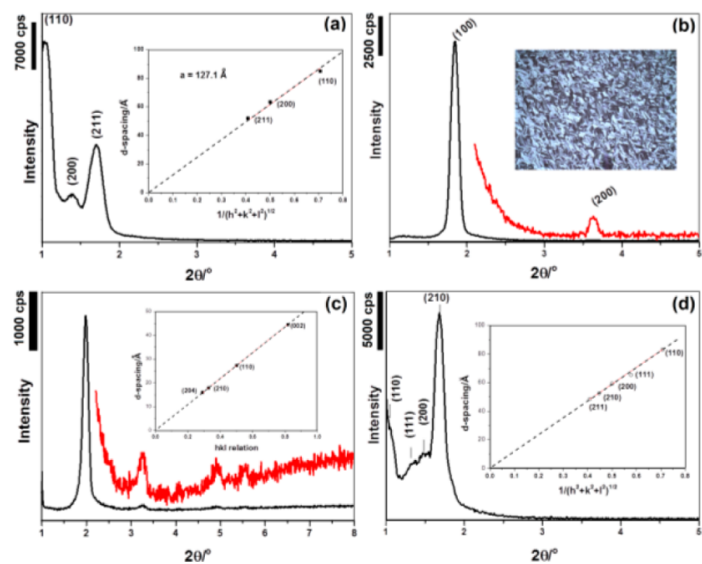

Figure 1. XRD patterns of the PANS-LLCMs with a PA/C ${ }_{12} E_{10}$ mole ratio of (a) 2, (b) 3, (c) 5, and (d) 6 . Insets are the plots of $d$-spacing versus $h k l$ relation of the corresponding structure.
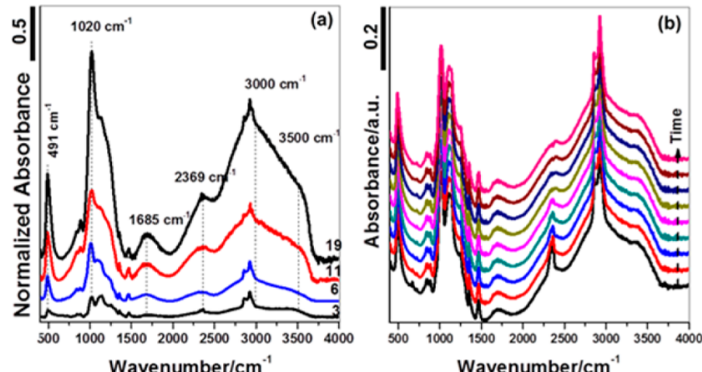

Wavenumber $/ \mathrm{cm}^{-1}$

Wavenumber $/ \mathrm{cm}^{-1}$

Figure 2. FT-IR spectra of the PANS-LLCMs with a PA/C ${ }_{12} \mathrm{E}_{10}$ mole ratio of (a) 3, 6, 11, and 19 and (b) FT-IR spectral changes of the PANS-LLCMs of a $4 \mathrm{PA} / \mathrm{C}_{12} \mathrm{E}_{10}$ mole ratio over time.

Note also that the hexagonal phases are birefringent and display a characteristic focal conic fan texture with a typical domain size of $10-100 \mu \mathrm{m}$; see inset in Figure $1 b$.

We also monitored the room-temperature behavior of the PANS-LLCMs using FT-IR spectroscop; see Figures 2 and S1. Figure 2a displays a set of FT-IR spectra of PANS-LLCMs with an increasing $P A / C_{12} E_{10}$ mole ratio. Clearly, the peaks related to the concentrated PA dominate the spectra with an increasing $P A / C_{12} E_{10}$ mole ratio, which closely resembles the spectrum of concentrated PA. These spectra show that the PA molecules form a network of hydrogen bonds with each other, water, and surfactant molecules in the mesophase; see Scheme 1. The peaks at 491 and 1020 and the broad peak around $1200 \mathrm{~cm}^{-1}$ are due to PA bending and stretching modes, respectively. ${ }^{34} \mathrm{The} \mathrm{OH}$ region is spread over a broad frequency range, indicating a strong hydrogen-bonding network with different strengths. The broad peak at around $1685 \mathrm{~cm}^{-1}$ is due to the $\mathrm{H}_{2} \mathrm{O}$ bending mode; the likely origin of such broadening and blue shift is that the water species are involved in the network and are partially protonated. The peaks at 2370,3000 , and $3500 \mathrm{~cm}^{-1}$ are due to various stretching modes of $\mathrm{PA}$ with some contribution from the stretching mode of water in the $\mathrm{PA}-\mathrm{H}_{2} \mathrm{O}$ 


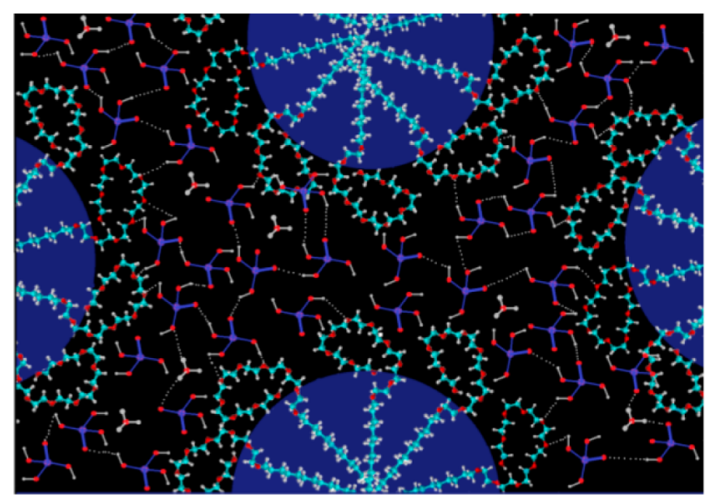

Scheme 1. Schematic representation of a hexagonal PANSLLCM.

network. $^{34}$ The stability and the response of PANSLLCMs to atmospheric conditions and to high humidity conditions (25-70\%) were also monitored over time using the samples spread over a Si wafer and with FT-IR spectroscopy; see Figures $2 \mathrm{~b}$ and $\mathrm{S} 1$. However, above $15 \mathrm{PA} / \mathrm{C}_{12} \mathrm{E}_{10}$ mole ratio the mesophase is not stable to high humidity. Figure $2 \mathrm{~b}$ clearly shows that there is almost no change in the spectra over 2 weeks under ambient laboratory conditions and only very little change in the extremely high PA containing samples, Figure S1. We also monitored PA itself over the Si wafer and noticed that within a few minutes it adsorbs so much water such that the sample flows from the silicon surface. This indicates that PANS-LLCMs do not demonstrate much response to atmospheric changes and are stable over very long periods.

The PANS-LLCMs are also stable over a very broad temperature range $\left(-100\right.$ to $\left.130^{\circ} \mathrm{C}\right)$, but they depend on the PA/ $\mathrm{C}_{12} \mathrm{E}_{10}$ mole ratio; the PANS-LLCM of low $\mathrm{PA} / \mathrm{C}_{12} \mathrm{E}_{10}$ mole ratio has been monitored under a POM using a temperature-controlled hot plate. Figure S2 shows a set of POM images recorded between RT and $-150{ }^{\circ} \mathrm{C}$. Clearly, the sample never loses its birefringence at any temperature. We also checked the isotropization or melting point of the mesophase, which increases with an increasing PA concentration up to 14 mole ratios and gradually decreases at higher concentrations, and becomes liquid at RT in the samples with 18-20 mole ratios. Moreover, these samples are gel-like at lower temperatures.

The ac proton conductivity measurements were carried out using two different homemade cells; see Figure S3 using impedance spectroscopy. See Supporting Information for details. Briefly, the conductivity increases with an increasing PA concentration, Figure $3 a$. The increase in the PA concentration induces conformational and phase changes and enables the hydrophilic domains to accommodate more PA molecules. Such a compact arrangement in the cubic phase likely decreases the intermolecular distance between neighboring PA molecules and, hence, makes the hopping of protons more feasible. In the Grotthuss pathway, ${ }^{35}$

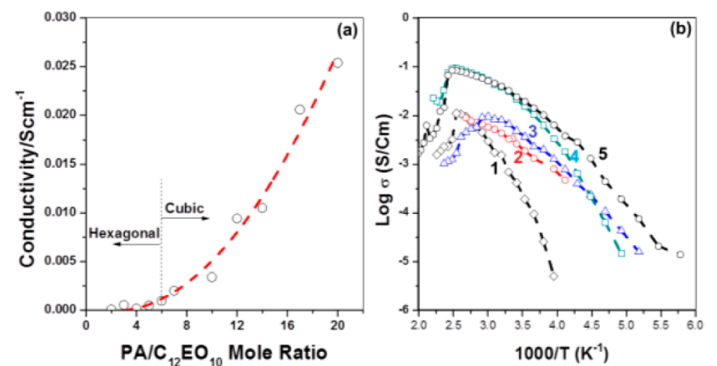

Figure 3. Alternating current conductivity plots of (a) increasing $\mathrm{PA} / \mathrm{C}_{12} \mathrm{E}_{10}$ mole ratio at $\mathrm{RT}$ and (b) $\log (\sigma)$ versus $1000 / T$ plots of PANS - LLCMs with a $P A / C_{12} E_{10}$ mole ratio of (1) 5, (2) 10, (3) 16, (4) 18, and (5) 20.

the conduction is facilitated by the hopping migration of protons, which require the close proximity of the ions involved, while in the vehicle pathway, the transportation of the proton is not affected by the absence of an infinite chain of hydrogen-bonded molecules. It requires only "vehicles" such as water, with high selfdiffusion constants, to facilitate the proton mobility. Therefore, if we assume the Grotthuss pathway, then the higher composition PANSs, which are more viscous, should definitely be more conductive. Recently, Dag et al. ${ }^{13}$ reported that from the lithium salt-surfactant mesophases the less viscous samples are more conductive because of the high ionic mobility associated with the more liquid-like gels. Therefore, while the LLChydrated metal salts obeyed the "vehicle" mechanism of ion conductivity, the lower resistivity in the highly viscous PANS gels is based on the fact that they obey the Grotthuss conduction mechanism. ${ }^{35}$

The proton conductivity has been measured for all samples, but the temperature-dependent measurements were carried out for only five samples: $P A / C_{12} E_{10}$ mole ratio of $5,10,16,18$, and 20 , Figure $3 \mathrm{~b}$. The results showed that the gels remained conductive over a wide range of temperatures, depending on the compositions. The conductivity increases with an increasing temperature until a certain value (above the melting points), then starts decreasing again, showing either the complete evaporation of water from the samples or the collapse of the mesophase caused by melting. This behavior was observed in all compositions but at different temperatures, which led to the conclusion that the vaporization temperature was affected by the viscosity of the composition. For example, the more viscous, low-concentrated samples remain conductive even at temperatures above $130^{\circ} \mathrm{C}$, while the more fluid-like samples were resistive above $100^{\circ} \mathrm{C}$. In the low-temperature regions, it was also realized that the more concentrated (less viscous) samples showed reasonable conductivity $\left(7.6 \times 10^{-5} \mathrm{~S} / \mathrm{cm}\right)$ even at temperatures below $-80{ }^{\circ} \mathrm{C}$, while the lower concentrated samples show only fair conductivity at temperatures around $-30^{\circ} \mathrm{C}$.

It is already known that the increase in temperature causes the breakage of hydrogen bonds and, at the 
same time, enhances the conductivity of the materials. Therefore, the conductivity of the PANS gels, which we assume to be largely dependent on hydrogen-bonded networks, may be at odds with this already accepted belief. However, this could be explained when we consider the different conductivity mechanisms and the possibility of changing from one mechanism to the other. When the gels completely melt, the decrease in the activation energy coupled with the fast mobility of the "vehicles" will enhance the proton conductivity even more. Therefore, the vehicle's mechanism, which requires higher activation energy, will be the preferred mode of conduction in such a situation. This is what led to the observed rise in conductivity and non-Arrhenius behavior as a function of temperature in the viscous gels. This behavior continues until the gel-like liquid starts losing water molecules to the atmosphere and causes a " $\mathrm{V}$ " shape in the higher temperature regions; see Figure $3 \mathrm{~b}$. On the other hand, when the temperature was reduced to temperatures much lower than $0{ }^{\circ} \mathrm{C}$, the resistance sharply increased. One of the factors that might be responsible for this sharp change is the decrease in the mobility of the carriers at temperatures below the freezing point of the gel or the formation of cracks (upon freezing) in the samples. In either case, semicircular arcs, showing bulk impedance of the sample, were observed in the high-frequency regions of all the samples that were completely frozen. The temperature-dependent conductivity plots show a non-Arrhenius behavior. This is known for PA in various media. ${ }^{29-32}$ The conductivity is Arrhenius below the glass transition temperatures, and the conduction takes place via a hopping mechanism (Grotthuss mechanism). ${ }^{35}$ Two different proton conductivity mechanisms (namely "Grotthuss" and "vehicle" mechanisms) are responsible for the non-Arrhenius behavior at higher temperatures. ${ }^{30,35}$

We also employed the PANS-LLCMs as electrolytes in a graphene-based optical modulator and compared the performance of PANS with a well-known ionic liquid ( $N, N$-diethyl- $N$-methyl- $N$-(2-methoxyethyl)ammonium bis(trifluoromethanesulfonyl)imide). The graphene optical modulator is a supercapacitor formed by two graphene electrodes and an electrolyte between them (Figure 4a). ${ }^{36}$ The applied voltage between the graphene electrodes polarizes the electrolytes, which yields electrostatic doping on the graphene layers. Due to the low density of the states, the Fermi energy of the graphene shifts significantly under the electrostatic doping and results in the modulation of the optical transmittance owing to the Pauli blocking (see the inset in Figure 4b). The key challenge for the graphene modulator is to activate large doping concentrations with low applied voltages. The PANS electrolyte provides a very efficient device operation. The modulation of the optical transmittance is shown in Figure 4b. Transmittance in the visible and near-IR
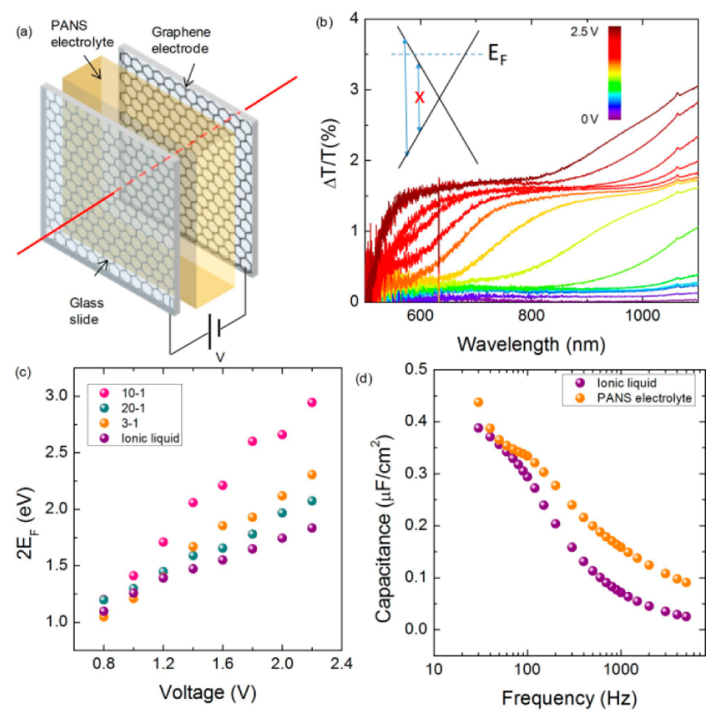

Figure 4. (a) Schematic view of the graphene supercapacitor that operates as an optical modulator. The device is formed by two graphene electrodes and a PANS electrolyte between them. (b) Variation of the optical transmittance in the visible and near-IR spectra with the applied voltage for the supercapacitors with the PANS (PA/C ${ }_{12} E_{10}=3$ ). The inset shows the schematic band structure of the doped graphene electrodes and blocked electronic transitions. (c) Extracted Fermi energy of graphene electrodes as a function of applied voltage for three different concentrations and representative ionic liquid. (f) Variation of capacitance of the modulator with the excitation frequency for a PANS electrolyte and the ionic liquid.

can be controlled by $1.7 \%$ (limited by the absorption of single-layer graphene) with relatively low voltages $(<3 \mathrm{~V})$. We compared the extracted Fermi energy of three PANS electrolyte concentrations with the ionic liquid electrolytes (Figure $4 \mathrm{c}$ ). PANS (PA/ $\mathrm{C}_{12} \mathrm{E}_{10}=10$ ) provides the best results, with Fermi energies up to $1.5 \mathrm{eV}$, which yield an optical modulation up to $500 \mathrm{~nm}$. Note that the Fermi energy $\left(E_{f}\right)$ has been measured from the transmittance spectrum, which shows a step-like function with a cut-off wavelength at $2 E_{\mathrm{f}}{ }^{36}$ Another advantage of the PANS over the ionic liquid is the high ionic mobility. Figure $4 \mathrm{~d}$ shows the frequencydependent capacitance of the modulator at $0 \mathrm{~V}$. PANS electrolytes yield relatively larger capacitance at kilohertz frequencies (see Figures S5 and S6 for details of the measurements). The device performance of the optical modulators has been compared using three different PANS. Figure $\mathrm{S} 7 \mathrm{a}-\mathrm{C}$ shows the optical transmittance through the modulator for the $P A / C_{12} E_{10}$ ratios of 3,10 , and 20 . Figure S7d compares the variation of the optical transmittance at $800 \mathrm{~nm}$ for the electrolytes.

\section{CONCLUSION}

In summary, PA and 10-lauryl ether form stable LLC mesophases over a very broad concentration range. The mesophases follow a general phase transition of $\mathrm{V}_{1}-\mathrm{H}_{1}-\mathrm{I}_{1}$ with increasing the PA content. 
The PANS-LLCMs have a high proton conductivity, which is based on the Grotthuss mechanism (protonhopping) at low temperatures and is based on both Grotthuss and vehicle mechanisms at higher temperature, and display non-Arrhenius behavior with increasing temperature. As an application, we fabricated graphene supercapacitors using PANS-LLCM electrolytes, which operate as optical modulators in the visible and near-IR spectra. We observed that PANS provides better device performance over ionic liquids in terms of operation wavelength and frequencies owing to the large ionic concentration and high proton conductivity.

\section{METHODS}

Preparation of PANS-LLCMs. A mixture of $7.000 \mathrm{~g}$ of water, $1.000 \mathrm{~g}$ of 10-lauryl ether, and phosphoric acid (for 19 different solutions the PA weights are $0.368,0.552,0.736,0.921,1.105$, $1.289,1.473,1.657,1.841,2.025,2.209,2.393,2.577,2.762,2.946$, $3.129,3.314,3.498$, and $3.682 \mathrm{~g}$, corresponding to $\mathrm{PA} / \mathrm{C}_{12} \mathrm{E}_{10}$ mole ratios of 2 to 20 with an increment of 1 , respectively) in a closed glass vial was stirred for about $5 \mathrm{~h}$. The homogenized solutions were spin-coated at a reasonable speed (500$700 \mathrm{rpm}$ ) on the surfaces of substrates (either glasses or silicon wafers). The gel phases (for conductivity, POM, and isotopization temperatures) were prepared by adding $1.000 \mathrm{~g}$ of 10 -lauryl ether to the required quantities of PA (exact values listed above). The mixtures were made airtight through the use of Teflon tape. All the vials containing different $\mathrm{PA} / \mathrm{C}_{12} \mathrm{E}_{10}$ ratios were put in a shaking water bath. The temperature of the bath was increased above the melting point of the surfactant $\left(40-50^{\circ} \mathrm{C}\right)$. This process took almost $24 \mathrm{~h}$ and resulted in the formation of highly viscous gels.

Preparation of Supercapacitors. Graphene layers used in the capacitors were synthesized by chemical vapor deposition on $25 \mu \mathrm{m}$ thick copper foils (Alfa Aesar Cu foil (item \#13382)) at $1050{ }^{\circ} \mathrm{C}$ under 10 Torr chamber pressure. Partial pressures of $\mathrm{CH}_{4}$ and $\mathrm{H}_{2}$ gases were set as 3 and 7 Torr, and corresponding rate of flows were 40 and $80 \mathrm{sccm}$, respectively. We transferred $1 \times 2 \mathrm{~cm}^{2}$ graphene layers on glass microscope slides by using an $\mathrm{S} 1813$ photoresist as a mechanical support for graphene. After drying the photoresist at $70^{\circ} \mathrm{C}$ for $12 \mathrm{~h}$ in the oven, the $\mathrm{Cu}$ foils were completely etched in the dense $\mathrm{FeCl}_{3}$ solution in $2 \mathrm{~h}$. Graphene holding the photoresist was reflowed at $110{ }^{\circ} \mathrm{C}$ to release the graphene layer on the microscope slide. The graphene-transferred microscope slides were put together by a $100 \mu \mathrm{m}$ thick spacer. The gap between the two graphene electrodes was filled with a gel electrolyte or a commercially available ionic liquid to compare the electrolyte performances.

Instrumentation. The XRD patterns were recorded using a Rigaku Miniflex diffractometer equipped with a high-power $\mathrm{Cu} \mathrm{K} \alpha$ source operating at $30 \mathrm{kV} / 15 \mathrm{~mA}$ and a wavelength of $1.5405 \AA$. The measurements for both the films and gel samples were done at a scan rate of $1 \theta / \mathrm{min}$ at 0.01 data intervals. The POM images were obtained in transmittance mode by using a ZEISS Axio Scope.A1 polarizing optical microscope. For measuring the isotropization temperatures of the samples, a Linkam LTS350 temperature-controlling stage was attached to the microscope, and the temperature was controlled using a LinkamT95-LinkPad temperature programmer attached to the stage. The cooling of the samples was achieved through the help of liquid $\mathrm{N}_{2}$ in a Dewar connected to the stage, and the $\mathrm{N}_{2}$ level of the environment was controlled with a temperaturecooling chamber to make a $100 \% \mathrm{~N}_{2}$ environment. The heating and cooling procedures were varied between 1 and $5 \mathrm{deg} / \mathrm{min}$, and the images of the phase transitions were captured with an inbuilt camera, attached at the top of the microscope. Fourier transform infrared (FT-IR) spectra were recorded using a Bruker Tensor 27 model FT-IR spectrometer. A Digi Tect TM DLATGS detector was used with a resolution of $4.0 \mathrm{~cm}^{-1}$ in the $400-4000 \mathrm{~cm}^{-1}$ range. The spectra were recorded by spreading the samples on silicon wafers using 64,128 , or 256 scans. The micro-Raman spectra were recorded on a LabRam confocal Raman microscope with a $300 \mathrm{~mm}$ focal length. The spectrometer was equipped with a Ventus LP 532, $50 \mathrm{~mW}$, diodepumped solid-state laser operating at 20 to $34 \mathrm{~mW}$, with a polarization ratio of 100:1, a wavelength of $532.1 \mathrm{~nm}$, and a $1024 \times 256$ element CCD camera. The signal collected was transmitted via a fiber-optic cable into a spectrometer with a $600 \mathrm{~g} / \mathrm{mm}$ grating. The Raman spectra were collected by manually placing the probe tip on the desired point of the sample over the glass or silicon wafer. The conductivity measurements were performed by using a Gamry G750 potentiostat/galvanostat operating at an ac voltage of $10 \mathrm{mV}$ and within a frequency range of 0.1 to $300 \mathrm{kHz}$. The cells used in the instrument were all homemade, made from either one or two fluorine-doped tin oxide (FTO)-coated glass. For the case of the two-FTO-coated slides, the cell constants were determined from the cells' dimensions, while for the single-FTO case, the cell constants were determined using a standard solution of $\mathrm{KCl}$ with a known conductivity value. In the two-electrode system, the reference and counter (short-cut) electrode were attached to one of the FTO-coated slides, while the working electrode was attached to the other. On the other hand, both the shortcut electrodes (reference and counter) and the working electrodes were attached to the same FTO, one on either side, in the single-FTO system. The optical transmission measurements were performed over a broad range $(450$ to $1100 \mathrm{~nm})$ by using a Bruker Vertex 70 V FT-IR spectrometer equipped with a Si photodiode. The bias voltage was applied by a source measure unit (Keithley 2400), and the leakage current was also monitored during the transmission measurements to observe the proper device operation. An HP 4284A precision LCR meter, which is programmed to measure the parameters of a serially connected capacitor-resistor network model, was used in capacitance and resistance measurements of the graphene supercapacitors.

Conflict of Interest: The authors declare no competing financial interest.

Supporting Information Available: Composition- and timedependent FT-IR spectra, temperature-dependent POM images, setups for conductivity measurements, Nyquist plots, and extra optical and electrical characteristics of the graphene supercapacitor. This material is available free of charge via the Internet at http://pubs.acs.org.

Acknowledgment. Authors thank TUB ITAK under the project number $113 Z 730$ for financial support. E.T. thanks IDB for the M.Sc. scholarship. Ö.D. is a member of Science Academy, Istanbul, Turkey.

\section{REFERENCES AND NOTES}

1. Mitchell, D. J.; Tiddy, G. J. T.; Waring, L.; Bostock, T.; McDonald, M. P. Phase Behavior of Polyoxyethylene Surfactants with Water. Mesophase Structures and Partial Miscibility (Cloud Points). J. Chem. Soc., Faraday Trans. 1 1983, 79, 975-1000.

2. Dong, R.; Hao, J. Complex Fluids of Poly(oxyethylene) Monoalkyl Ether Nonionic Surfactants. Chem. Rev. 2010, 110, 4978-5022.

3. Alexandridis, P.; Zhou, D.; Khan, A. Lyotropic Liquid Crystallinity in Amphiphilic Block Copolymers: Temperature Effects on Phase Behavior and Structure for Poly(ethylene oxide)-b-Poly(propylene oxide)-b-Poly(ethylene oxide) Copolymers of Different Composition. Langmuir 1996, $12,2690-2700$.

4. Alexandridis, P.; Olsson, U.; Lindman, B. A Record Nine Different Phases (Four Cubic, Two Hexagonal, and 
One Lamellar Lyotropic Liquid Crystalline and Two Micellar Solutions) in a Ternary Isothermal System of an Amphiphilic Block Copolymer and Selective Solvents (Water and Oil). Langmuir 1998, 14, 2627-2638.

5. Weckström, K.; Zulauf, M. Lower Sonsolute Boundaries of a Poly(oxyethylene) Surfactant in Aqueous Solution of Monovalent Salts. J. Chem. Soc., Faraday Trans. 1 1985, 81, 2947-2958.

6. Zheng, L.-Q.; Minamikawa, H.; Harada, K.; Inoue, T.; Chernik, G. G. Effect of Inorganic Salts on the Phase Behavior of an Aqueous Mixture of Heptaethylene Glycol Dodecyl Ether. Langmuir 2003, 19, 10487.

7. Inoue, T.; Yokoyama, Y.; Zheng, L.-Q. Hofmeister Anion Effect on Aqueous Phase Behavior of Heptaethylene Glycol Dodecyl Ether. J. Colloid Interface Sci. 2004, 274, 349-353.

8. Greaves, T. L.; Drummond, C. J. Ionic Liquids As Amphiphile Self-Assembly Media. Chem. Soc. Rev. 2008, 37, 1709-1726.

9. Ichikawa, T.; Yoshio, M.; Hamasaki, A.; Mukai, T.; Ohno, H.; Kato, T. Self-Organization of Room Temperature Ionic Liquids Exhibiting Liquid Crystalline Bicontinuous Cubic Phases: Formation of Nano-lon Channel Networks. J. Am. Chem. Soc. 2007, 129, 10662-10663.

10. Hollamby, M. J.; Trickett, K.; Mohamed, A.; Eastoe, J.; Rogers, S. E.; Heenan, K. Surfactant Aggregation in $\mathrm{CO}_{2} /$ Heptane Solvent Mixtures. Langmuir 2009, 25, 1290912913.

11. Çelik, Ö.; Dag, Ö. A New Lyotropic Liquid Crystalline System:

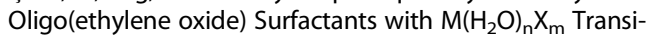
tion Metal Complexes. Angew. Chem., Int. Ed. 2001, 40, 3800-3803.

12. Albayrak, C.; Özkan, N.; Dag, Ö. Origin of Lyotropic Liquid Crystalline Mesophase Formation and Liquid Crystalline to Mesostructured Solid Transformation in the Metal Nitrate Salt-Surfactant Systems. Langmuir 2011, 27, 870-873.

13. Albayrak, C.; Cihaner, A.; Dag, Ö. A Highly Conductive Lithium Salts-Non-lonic Surfactants Lyotropic Liquid Crystalline Mesophases and Its Application. Chem.-Eur. J. 2012, 18, 4190-4193.

14. Attard, G. S.; Glyde, J. C.; Göltner, C. G. Liquid-Crystalline Phases As Templates for the Synthesis of Mesoporous Silica. Nature 1995, 378, 366-368.

15. Yamauchi, Y.; Momma, T.; Yokoshima, T.; Kuroda, K.; Osaka, T. Highly Ordered Mesostructured Ni Nanoparticles Prepared from Lyotropic Liquid Crystals by Electroless Deposition: The Effect of Reducing Agents on the Ordering of Mesostructure. J. Mater. Chem. 2005, 15, 1987-1994.

16. Türker, Y.; Dag, Ö. Synthesis of Mesostructured Metal Sulfide Films Using $\left[\mathrm{M}\left(\mathrm{H}_{2} \mathrm{O}\right)_{n}\right]\left(\mathrm{NO}_{3}\right)_{2}: \mathrm{P} 85(\mathrm{M}=\mathrm{Cd}(\mathrm{II})$ and $\mathrm{Zn}(\mathrm{II}))$ Liquid Crystalline Mesophases. J. Mater. Chem. 2008, 18, 3467-3473.

17. Radhakrishnan, L.; Wang, H.; Yamauchi, Y. Precise Manipulation of One-Dimensional Mesochannel Alignments in Mesoporous Silica Films by Novel Rubbing Method. Chem.-Asian J. 2010, 5, 1290-1293.

18. Yamauchi, Y. Field-Induced Alignment Control of OneDimensional Mesochannels in Mesoporous Materials. J. Ceram. Soc. Jpn. 2013, 121, 831-840.

19. Attard, G. S.; Barlett, P. N.; Coleman, N. R. B.; Elliott, J. M.; Owen, J. R. Lyotropic Liquid Crystalline Properties of Non lonic Surfactant $/ \mathrm{H}_{2} \mathrm{O} /$ Hexachloroplatinic Acid Ternary Mixtures Used for the Production of Nanostructured Platinum. Langmuir 1998, 14, 7340-7342.

20. Ichikawa, T.; Kato, T.; Ohno, H. 3D Continuous Water Nano-Sheet as a Gyroid Minimal Surface Formed by Bicontinuous Cubic Liquid-Crystalline Zwitterions. J. Am. Chem. Soc. 2012, 134, 11354-11357.

21. Soberats, B.; Yoshio, M.; Ichikawa, T.; Taguchi, S.; Ohno, H.; Kato, T. 3D Anhydrous Proton-Transporting Nanochannels Formed by Self-Assembly of Liquid Crystals Composed of a Sulfobetaine and a Sulfonic Acid. J. Am. Chem. Soc. 2013, 135, 15286-15289.

22. Acımıs, M. Micellar Phases Formed by a Solution of 1-Serine Hydrochloride Decylester and Orthophosphoric Acid. Liq. Cryst. 1987, 2, 549-552.
23. Xu, Y.; Gu, W.; Gin, D. L. Heterogeneous Catalysis Using a Nanostructured Solid Acid Resin Based on Lyotropic Liquid Crystals. J. Am. Chem. Soc. 2004, 126, 1616-1617.

24. Zhou, W.; Gu, W.; Xu, Y.; Pecinovsky, C. S.; Gin, D. L. Assembly of Acidic Amphiphiles into Inverted Hexagonal Phases Using an L-Alanine-Based Surfactant as a StructureDirecting Agent. Langmuir 2003, 19, 6346-6348.

25. Soberats, B.; Uchida, Emi.; Yoshio, M.; Kagimoto, J.; Ohno, H.; Kato, T. Macroscopic Photocontrol of lon-Transporting Pathways of a Nanostructured Imidazolium-Based Photoresponsive Liquid Crystal. J. Am. Chem. Soc. 2014, 136, 9552-9555.

26. Wang, L. M.; He, F.; Richert, R. Intramicellar Glass Transition and Liquid Dynamics in Soft Confinement. Phys. Rev. Lett. 2004, 92, 095701-4.

27. Blochowicz, T.; Gouirand, E.; Fricke, A.; Spehr, T.; Stühn, B.; Frick, B. Accelerated Dynamics of Supercooled Glycerol in Soft Confinement. Chem. Phys. Lett. 2009, 475, 171-174.

28. Albayrak, C.; Barım, G.; Dag, Ö. Effect of Hygroscopicity of the Metal Salt on the Formation and Air Stability of Lyotropic Liquid Crystalline Mesophases in Hydrated SaltSurfactant Systems. J. Colloid Interface Sci. 2014, 433, 26-33.

29. Wang, Y.; Lane, N. A.; Sun, C. N.; Fan, F.; Zawodzinski, T. A.; Sokolov, A. P. lonic Conductivity and Glass Transition of Phosphoric Acids. J. Phys.Chem. B 2013, 117, 8003-8009.

30. Kreuer, K.-D. Proton Conductivity: Materials and Applications. Chem. Mater. 1996, 8, 610-641.

31. Kreuer, K.-D.; Paddison, S. J.; Spohr, E.; Schuster, M. Transport in Proton Conductors for Fuel-Cell Applications: Simulations, Elementary Reactions, and Phenomenology. Chem. Rev. 2004, 104, 4637-4678.

32. Vilciauskas, L.; Tuckerman, M. E.; Bester, G.; Paddison, S. J.; Kreuer, K.-D. The Mechanism of Proton Conduction in Phosphoric Acid. Nat. Chem. 2012, 4, 461-466.

33. Yang, D.; Lu, Z.; Rui, X.; Huang, X.; Li, H.; Zhu, J.; Zhang, W.; Lam, Y. M.; Hng, H. H.; Zhang, H.; Yan, Q. Synthesis of Two-Dimensional Transition-Metal Phosphates with Highly Ordered Mesoporous Structure for Lithium Ion Battery Applications. Angew. Chem., Int. Ed. 2014, 53, 9352-9355.

34. Fadeeva, Y.; Safonova, L. P.; Persson, I. Physico-Chemical and Structural Characterization of the Binary System Phosphoric Acid-N,N-Dimethylformamide. Phys. Chem. Chem. Phys. 2010, 12, 8977-8984.

35. Kreuer, K.-D.; Rabenau, A.; Weppner, W. Vehicle Mechanism, a New Model for the Interpretation of the Conductivity of Fast Proton Conductors. Angew. Chem., Int. Ed. Engl. 1982, 21, 208-209.

36. Polat, E. O.; Kocabas, C. Broadband Optical Modulators Based on Graphene Supercapacitors. Nano Lett. 2013, 13, 5851-5857. 